\title{
Exercise as a favorable non-pharmacologic treatment to Sleep-Related Movement Disorders: a review
}

Beatriz Franco ${ }^{1}$

Paulo Daubian-Nosé2

Marco Túlio De-Mello ${ }^{3}$

Andrea Maculano Esteves ${ }^{2}$

${ }^{1}$ Universidade Estadual de Campinas, Faculdade de Educação Física Campinas - São Paulo - Brazil.

${ }^{2}$ Universidade Estadual de Campinas, Faculdade de Ciências Aplicadas Limeira - São Paulo - Brazil.

${ }^{3}$ Universidade Federal de Minas Gerais, Professor Associado II do Departamento de Esportes, da Escola de Educação Física, Fisioterapia e Terapia Ocupacional - Belo Horizonte Minas Gerais - Brazil.

Corresponding author: Andrea Maculano Esteves. E-mail: andrea.esteves@fca.unicamp.br Received: january 22, 2018; Accepted: april 03, 2019.

\begin{abstract}
Non-pharmacologic treatments of Sleep-Related Movement Disorders (SRMD) are already well described in the literature. The physical activity has been presented as a factor to improve quality of life and in several aspects related to sleep disorders. Thus, the purpose of this review was to analyze the benefits of physical exercise and your indication to improve to SRMD. In the research, 19 studies were found that evaluate the efficacy of physical exercise on SRMD in both human and animal models. The results demonstrate that both acute and chronic physical exercises are effective in reducing symptoms of SRMD. However, most studies were performed with aerobic exercise. Three studies evaluated the efficacy of combined exercise, and no studies have investigated the relationship of resistance exercise. Regarding the mechanisms involved, a study discusses the relationship between the release of beta-endorphin and the exercise practice, and two studies with animal models show the changes of the dopaminergic system after physical exercise. From this evidences, we suggested that physical exercise is a favorable non-pharmacological treatment for SRMD. However, more studies should be available for a better understanding of the molecular mechanisms involved, as well of the type, duration and better time of the day to practice.
\end{abstract}

Keywords: Restless Legs Syndrome; Movement Disorders; Physical Exercise; Sleep Wake Disorders. 


\section{INTRODUCTION}

Sleep-Related Movement Disorders (SRMD) is characterized by simple, often stereotyped movements related to sleep $^{1}$. Among them, we can highlight the Restless Legs Syndrome (RLS) and Periodic Leg Movement (PLM).

The RLS is a common neurological movement disorder characterized by motor restlessness resulting in an uncontrolled urge to move the mostly the legs, causing difficulty in initiating sleep ${ }^{2,3}$. Already the PLM is characterized by involuntary movements caused by specific muscle contractions that occur during sleep causing nocturnal awakenings ${ }^{4,5}$.

Most people with RLS also have Periodic Legs Movements ${ }^{6 .}$ Some studies demonstrate variability in the prevalence of these sleep disorders. According to Kuchukhidze et al.but unknown in Georgia. This pilot study aimed to assess RLS prevalence in a focused Georgian population. Methods: An RLS epidemiological questionnaire [Allen et al.: Sleep Med 2003;4:101119] was filled out by patients in five primary healthcare centers in two Georgian cities between March and September 2006. Additionally, questions related to RLS symptom onset, family history, treatment, sleep disturbance and history of iron deficiency were included. RLS diagnosis was based on an expert interview and an epidemiological questionnaire for RLS. Results: The total number of respondents was 115 (75\% women/25\% men ${ }^{7}$ prevalence in different proportions was explained by various studies, methods, genetic predisposition, ethnicity and environment factors, and according to Montplaisir et al. ${ }^{6}$, the symptoms often start in childhood and adolescence.

Shin et al. ${ }^{8}$ found that the prevalence of PLMS in Korean patients it was lower than that reported in patients from Western countries. According to Phillips et al.often accompanied by daytime behavioral problems. Treatment for this condition is available, but it is suspected that most instances of RLS remain undiagnosed. The goal of this investigation was to assess the prevalence and health status correlates of restless legs symptoms (hereinafter referred to as restless legs $9 \%$ of participants aged 18 to 29 years, $10 \%$ of those aged 30 to 79 years and $19 \%$ of those 80 years old related experiencing RLS five or more nights per month. The prevalence estimated by Ohayon et al.RLS has been studied as: $1^{3}$ ranged between $1.9 \%$ and $15 \%$ in four different cases in the general adult population, and the prevalence of RLS is higher in women than in men.

The main causes of RLS are passing through transmission, change in brain iron homeostasis, and related to this change, a dopaminergic dysfunction, glutamatergic and adenosinérgica ${ }^{10-14}$. The alterations found in studies related to these systems are: increased levels of presynaptic dopamine, decreased dopamine receptor $\mathrm{D} 2^{12}$, increased activity of tyrosine hiroxilase ${ }^{11}$, increased glutamate ${ }^{15}$ and reduces adenosine activity ${ }^{14}$. However, these changes are not fully understood, and little is known about the impact of physical exercise on these mechanisms altered by RLS and PLM.

Different treatments are proposed to reduce the symptoms of RLS and PLM index. Winkelman et al. ${ }^{16}$ describe the significant benefits of dopamine and opioid agonists, vitamins
$\mathrm{C}$ and $\mathrm{E}$, and iron treatment. Alternative types of non-pharmacologic therapy are also suggested like sleep hygiene, lifestyle interventions, yoga, acupuncture, near-infrared light, melatonin, vitamins, cold shower, brief walk before bedtime and Chinese herbs to improve RLS symptoms and PLM index ${ }^{17}$. However, it seems that the physical exercise has been more efficient among the alternatives treatments ${ }^{18-21}$. Additionally, several studies performed with animal models elucidated the mechanisms and anticipated benefits of the physical exercise in the SRMD symptoms.

Thus, the purpose of this narrative review is clear the benefits of physical exercise and your indication to improve RLS symptoms and PLM index and demonstrate different methods and types of physical exercise, impact and duration and better time of the day to practice.

To perform this review, the key words: restless legs syndrome, periodic leg movement, physical exercise, non-pharmacologic treatment were used in the Pubmed platform (Table 1).

\section{ACUTE PHYSICAL EXERCISE}

\section{Human}

Some studies have evaluated whether only one exercise session would be enough to minimize the symptoms of RLS/ PLM.

Esteves et al. ${ }^{21}$ conducted a study with sedentary individuals diagnosed with PLM to evaluate the effects of a single maximum effort test (MET) on their sleep patterns. The individuals classified as mild PLM presented improvements with a significant difference in the wake after sleep onset (WASO), REM sleep and PLM index parameters when compared before and after the MTE session. However, the results of the volunteers classified as moderate and severe PLM showed no significant difference, but a trend of improvement was found in all parameters. Also, a significant negative correlation was found between PLM index and $\beta$-endorphin release, that is a single exercise session caused an increase in $\beta$-endorphin values and a decrease in PLM index.

Cavagnolli et al. ${ }^{22}$ obtained similar results with one of its objectives being to evaluate the influence of a single MET session on the sleep pattern of men diagnosed with PLM and the relationship with a density of the dopamine transporter (DAT) in the putamen. Their results demonstrated a significant increase in stage 1 of NREM (nonrapid eyes movement) sleep and a decrease in PLM index values of participants with PLM after MET. The group of patients with PLM showed lower numbers of DAT density against the control group, but a single exercise session was not enough to alter these values.

Giannaki et al. ${ }^{23}$ showed essential results in hemodialysis patients diagnosed with RLS/PLM. Volunteers were divided into three groups: two of them performed a physical exercise session (light and heavy), and the third group did not perform any type of exercise. The groups that performed the exercise showed significant differences in PLM index after the workout when compared to the group without exercise. 
Table 1. Studies Details.

\begin{tabular}{|c|c|c|c|c|}
\hline Study Details & N Validated & Experimental Model & Patient Detail (Humans) & Period and Type of Exercise \\
\hline $\begin{array}{l}\text { de Mello et al. } \\
\text { (2002) }\end{array}$ & 12 & None & $\begin{array}{l}\text { Complete spinal cord injury between } \mathrm{T} 7 \text { and } \\
\mathrm{T} 12\end{array}$ & $\begin{array}{c}\text { Chronic } \\
\text { Aerobic Exercise }\end{array}$ \\
\hline $\begin{array}{l}\text { de Mello et al. } \\
\text { (2004) }\end{array}$ & 13 & None & $\begin{array}{l}\text { Complete spinal cord injury between } \mathrm{T} 7 \text { and } \\
\text { T12 }\end{array}$ & $\begin{array}{c}\text { Chronic } \\
\text { Aerobic Exercise }\end{array}$ \\
\hline $\begin{array}{l}\text { Aukerman et al. } \\
(2006)\end{array}$ & 41 & None & Adults with RLS & $\begin{array}{c}\text { Chronic } \\
\text { Aerobic and Resistance Exercise }\end{array}$ \\
\hline $\begin{array}{l}\text { Esteves et al. } \\
\text { (2009) }\end{array}$ & 22 & None & Patients with PLM & $\begin{array}{l}\text { Acute/Chronic } \\
\text { Aerobic Exercise }\end{array}$ \\
\hline $\begin{array}{l}\text { Giannaki et al. } \\
\text { (2010) }\end{array}$ & 18 & None & Patients on hemodialysis & $\begin{array}{c}\text { Acute } \\
\text { Aerobic and Resistance Exercise }\end{array}$ \\
\hline $\begin{array}{l}\text { Esteves et al. } \\
\text { (2011) }\end{array}$ & 11 & None & Adults with RLS & $\begin{array}{c}\text { Chronic } \\
\text { Aerobic Exercise }\end{array}$ \\
\hline $\begin{array}{l}\text { Giannaki et al. } \\
\text { (2013) }\end{array}$ & 24 & None & Patients with uraemic restless legs syndrome & $\begin{array}{l}\text { Chronic } \\
\text { Aerobic Exercise }\end{array}$ \\
\hline $\begin{array}{l}\text { Giannaki et al. } \\
\text { (2013) }\end{array}$ & 32 & None & $\begin{array}{l}\text { Hemodialysis patients with restless legs } \\
\text { syndrome }\end{array}$ & $\begin{array}{c}\text { Chronic } \\
\text { Aerobic Exercise }\end{array}$ \\
\hline $\begin{array}{l}\text { Mortazavi et al. } \\
(2013)\end{array}$ & 26 & None & End stage renal disease patients & $\begin{array}{c}\text { Chronic } \\
\text { Aerobic Exercise } \\
\end{array}$ \\
\hline $\begin{array}{l}\text { Simon et al. } \\
(2013)\end{array}$ & 25 & None & $\begin{array}{c}\text { Patients accurately complaining of Exercise } \\
\text { Intolerance }\end{array}$ & $\begin{array}{c}\text { Chronic } \\
\text { Aerobic and Resistance Exercise }\end{array}$ \\
\hline $\begin{array}{l}\text { Esteves et al. } \\
(2014)\end{array}$ & 221 & None & Adult sedentary volunteers & $\begin{array}{c}\text { Acute } \\
\text { Aerobic and Resistance Exercise }\end{array}$ \\
\hline $\begin{array}{l}\text { Frank et al. } \\
\text { (2016) }\end{array}$ & 80 & Male NWRs and SHRs & None & $\begin{array}{c}\text { Chronic } \\
\text { Aerobic Exercise }\end{array}$ \\
\hline
\end{tabular}

Esteves et al..$^{24}$ conducted a study with individuals with and without PLM, where participants were divided between a single resistance exercise session, aerobic exercise, and interval exercise. Also, participants were divided by practice time (morning, afternoon or evening). The results showed that, regardless of the type of exercise, all participants (with and without PLM) who practiced at night had a decrease in sleep latency in the night after the exercise session. The group with and without PLM, regardless of time and type of exercise, had an increase in REM (rapid eye movement) sleep on the night after exercise. The PLM group did not improve PLM index.

A study with spinal cord injuries (T7- T12), by de Mello et al. ${ }^{25}$, showed that after a test of incremental maximum effort session, participants had significant improvements in total sleep time (TST), REM sleep time, number of awakenings and the PLM index.
Facing with the results of studies with acute exercise used in this review, it was revealed that all had results with improvements in sleep, such as increased total sleep time or even the reduction of periodic leg movements. Only two studies performed physiological analyzes. The study Esteves et al. ${ }^{21}$ found correlation of PLM decrease with the increase of beta-endorphin levels, where beta-endorphin is a neurotransmitter found in the nervous system responsible for feelings of relaxation and well-being 45 , can then have helped in improving the symptoms of this disorder of sleep-related movement. In the other study conducted by Cavagnolli et al. ${ }^{22}$, DAT analysis was performed, which is the dopamine transporter responsible for the reuptake of dopamine in the synaptic cleft for the presynaptic, and a reduction of this transporter was found in patients with RLS, but without alteration after exercise. DAT alterations have already been found in other studies ${ }^{12,13}$ in patients with RLS; however, 
the role of DAT in physical exercise and in the improvement of symptoms caused by it is still unknown.

Until the moment, there are few studies in patients SPI and acute physical exercise, especially with physiological and molecular analysis to help understand the mechanisms responsible for the improvement of RLS symptoms and PLM.

\section{CHRONIC PHYSICAL EXERCISE}

\section{Animal Model}

Chronic physical exercise has been observed as a possible treatment to minimize the symptoms of RLS and PLM index. In this context, animal models are essential to improve means and methods of treatment, to search new lines of investigations and different protocol.

Esteves et al. ${ }^{26}$ conducted a study in Spontaneously Hypertensive Rats (SHR), considered a RLS animal model. The sleep patterns were based on the simultaneous analyses of electrocorticographic and limb electromyographic signals. As a form of acute pharmacological manipulation, the animals were treated with pramipexole; as a non- pharmacological treatment, the animals were subjected to four weeks of physical exercise. The results showed that the number of limb movement (LM) was reduced when the animals were submitted to a physical exercise treatment (five sessions per week during four weeks), and pramipexole treatment significantly attenuated the increased wakefulness presented by the SHRs before the beginning of the predominant sleep period (light period) when compared with the normotensive Wistar rats (NWR) group.

Frank et al. ${ }^{27}$ analyzed the physical exercise and pharmacological treatment (enalapril) for an animal model of SRMD (SHR). The results showed that physical exercise (8 weeks) and enalapril conferred protection for both hypertension and the observed behavioral changes. In addition, these treatments led to changes in dopaminergic signaling in the striatal region (D2 receptor, TH, and DAT). The locomotor activity was evaluated in an open field test, and blood pressure was assessed by tail plethysmography.

In addition, these treatments carried out separately led to changes in striatal dopaminergic signaling in the region, increasing levels of D2 receptor, DAT TH and analyzed by western blotting. The authors believe that training and enalapril regulate somehow dopaminergic dysfunction, and that this regulation may be due to changes in D2, TH and DAT leading to increased dopamine in the striatum.

Esteves et al. $^{28}$ found that the number of Limb Movements in Wistar rats with an A11 lesion that had performed physical exercise (5 x per week - moderate intensity) reduced substantially with six weeks of treadmill physical exercise. The sleep of was verified by Polysomnographic and the physical exercise was performed before and after the injury in the A11 nuclei. The findings consistently demonstrate that non-pharmacological manipulations had a beneficial effect on the symptoms of SRMD.

Animal studies have shown that physical exercise causes changes in the dopaminergic system, such as increase in dopamine, increase of D2 and decrease of DAT ${ }^{29,30}$. However, there are few studies with animal models for movement disorders related to sleep, physical exercise and dopaminergic system, making it difficult to understand the possible mechanisms associated with the improvement of symptoms by training.

\section{Human}

The chronic physical exercise is considerate a positive agent for treatment of several diseases. This function has also considered when analyzing RLS and PLM.

In the study conducted by de Mello et al. ${ }^{18}$, the researchers found decreased results on PLM/h when submitted male individuals with complete spinal cord injury between $\mathrm{T} 7$ and T12 to execute a physical training program for 44 days using an arm crank ergometer.

Two years later de Mello et al. ${ }^{19}$ verified one more time the benefits of physical exercise in patients with spinal cord injury. All volunteers were submitted to the administration of LDOPA and physical training. L-DOPA $(200 \mathrm{mg})$ in combination with benserazide chloride $(50 \mathrm{mg})$, or placebo was administered for 30 days, $1 \mathrm{~h}$ prior to sleeping time. This period of drug administration was followed by a 15-day washout period to physical exercise. The authors of both studies associate the decrease of PLM with the release of beta-endorphin and dopamine from exercise, where beta-endorphin interacts with opioid receptors in the brain, and the increase in dopamine results in a neurochemical balance that prevents the occurrence of these movements during sleep. The result of the increase in dopamine caused by exercise seems to be the same caused by dopaminergic agonists, used as pharmacological treatment of RLS and PLM.

Aukerman et al. ${ }^{31}$ showed in humans a randomized controlled trial of 12 weeks consisted of resistance exercises and aerobic exercise performed three times a week, and the exercise group had a significant improvement in symptoms compared with the control group according to IRLSSG scale. The authors report the importance of further studies with these sleep-related movement disorders and physical exercise, since the effects caused are promising, considering the numerous advantages that are known about exercise in sleep and in the cardiovascular, metabolic and musculoskeletal systems.

In a study conducted by Esteves et al. ${ }^{21}, 11$ sedentary volunteers were submitted to the chronic physical exercise $(72$ sessions of aerobic training for six months), the results showed a reduction in sleep latency, increasing in sleep efficiency and REM sleep and a decrease of PLM index. The authors suggested that physical exercise may be a plausible alternative to pharmacological treatment or may be used as a complement in severe cases of PLM. Another study ${ }^{32}$ conducted by the same group of researchers, using the IRLSS questionnaire, demonstrated that aerobic physical exercise performed at the intensity of the anaerobic ventilatory threshold was effective in reducing the symptoms of RLS after 36 sessions of aerobic physical exercise.

Several studies were performed with hemodialysis patients. Sakkas et al. ${ }^{2}$ realized a longitudinal study and the results 
revealed 16-week aerobic training improves RLS symptoms, functionality and exercise capacity, suggesting a significant improvement in the quality of life of patients with dialysis RLS. Mortazavi et al. ${ }^{33}$ developed a study where twenty-six patients were included and randomly divided into control group (13 patients) and exercise group (13 patients). Aerobic exercise was used during their hemodialysis for 16 weeks, and the patients pedaled three times per week during 30 minutes. At the end of the study, researchers suggested using aerobic exercise for improving signs of RLS.

Giannaki et al. ${ }^{34}$ conducted a study during six months with three times per week of cycling in patients with uremic restless legs syndrome, and the results showed that physical exercise was effective in reducing the symptom of the syndrome in $46 \%$. According to authors, 6-months intradialytic progressive exercise training program has a useful approach to reduce RLS symptom severity in hemodialysis patients. In the same year, Giannaki et al. ${ }^{35}$ found one more time that 6-months exercise training regimen was effective at a 6 -month low dosage dopamine agonist treatment in reducing restless legs syndrome and improving depression score in uremic patients.

Aliasgharpour et al. ${ }^{36}$ conducted a study with 33 hemodialysis patients from the hemodialysis of Tehran Hospital. They divided the patients between the control group and intervention group, and the results showed that stretching exercises on legs during hemodialysis three times per week over eight weeks could help alleviate the severity of RLS symptoms.

Giannaki et al. ${ }^{37}$ did a study with patients with RLS being on hemodialysis and found that the combination of low-dose ropinirole and aerobic exercise training can reduce RLS symptoms as well as the combination of aerobic exercise with placebo. One more time the importance and the efect of physical exercise proved to reduce the symptoms of SRMD.

The results of the cited studies of chronic exercise were diverse and different. This is due to the use of different methodologies and populations (sometimes even with other pathologies) and by different exercise protocols. However, in general, all studies have shown physical exercise as a tool to improve the symptoms of RLS and PLM.

\section{CONCLUSION}

The efficacy of physical exercise was evaluated in 19 studies (human and animal model) demonstrating that the severity of RLS/PLM symptoms can be significantly ameliorated by this non-pharmacologic treatment.

There are few studies that analyzed mechanisms involved in improving the symptoms of RLS and PLM index with acute and chronic physical exercise. Only one human study demonstrated the relationship of beta-endorphin release in aerobic physical exercises with the reduction of PLM index ${ }^{21}$. The role of the opioid and dopaminergic system in the pathophysiology of RLS/PLM is not fully understood in the literature however treatment with opioids and dopamine resulted in a satisfactory improvement of RLS symptoms/PLM severity ${ }^{38,39}$. Interestingly, in a study carried out with animal models (SHR) it was verified changes in dopaminergic signaling in the striatal region (D2 receptor, TH, and DAT) after eight weeks of treadmill physical exercise ${ }^{27}$. Studies in animal models bring us new perspectives of further investigations related to the physiological mechanisms, where it is possible to analyze the relation of the expression of proteins that are involved in the pathophysiology of this SRMD.

In addition, the evidence is lacking about the efficacy of resistance and combined exercises in the RLS/PLM symptoms. We found only two studies that demonstrated the effectiveness of combined physical exercise $\mathrm{e}^{24,31}$ and no studies had demonstrated the effects of resistive physical exercise on the reduction of RLS/PLM symptoms.

Another critical point is the relation of physical exercise intensity and the improvement of SRMD symptoms. A review by Hening ${ }^{40}$ demonstrated that patients experience an increase of symptoms later in the evening, after extensive exercise during the day. However, three studies reported that after the single maximum effort test (MET) ${ }^{21,22}$, or heavy exercise - cycling for 45 minutes with a resistance set at $60 \%{ }^{26}$, showed that patients presented reduction of the PLM index.

In this context, it should be noted that there is still little research being conducted to verify physical exercise treatment effects on RLS/PLM. Some results showed that this relationship is positive and promising. Nevertheless, there is a lack of studies with other populations that present RLS / PLM, such as pregnant women, children, and even secondary RLS, also, to it is essential to tailor physical exercise to the need of each patient. In addition, new mechanisms (dopaminergic, glutamatergic and adenosinergic alterations) are being associated with these disorders, but the findings are new and not fully understood, and little is known about their relationship with physical exercise in the improvement of RLS symptoms and PLM.

Thus, future studies are needed to clarify that molecular mechanisms are involved in the relationship of physical exercise in improving the SRMD symptoms, as well as further clarification about types of physical exercise, duration and better time of the day to practice.

Acknowledgment: Laboratório de Sono e Exercício Físico (LASEF) and Centro de Pesquisa em Ciências do Esporte (CEPECE). The authors also thank Cleide Lopes Jost for the language services provided.

\section{REFERENCES}

1. Sateia MJ. International classification of sleep disorders-third edition: highlights and modifications. Chest. 2014;146(5):1387-94. DOI: 10.1378 / chest.14-0970

2. Sakkas GK, Hadjigeorgiou GM, Karatzaferi C, Maridaki MD, Giannaki CD, Mertens PR, et al. Intradialytic aerobic exercise training ameliorates symptoms of restless legs syndrome and improves functional capacity in patients on hemodialysis: a pilot study. ASAIO J. 2008;54(2):185-90. DOI: 10.1097/MAT.0b013e3181641b07

3. Ohayon MM, O'Hara R, Vitiello MV. Epidemiology of restless legs syndrome: a synthesis of the literature. Sleep Med Rev. 2012;16(4):283-95 DOI: 10.1016/j.smrv.2011.05.002

4. Karadeniz D, Ondze B, Besset A, Billiard M. Are periodic leg movements during sleep (PLMS) responsible for sleep disruption in insomnia patients? Eur J Neurol. 2000;7(3):331-6. DOI: 10.1046/j.1468 1331.2000.00070 
5. Moore H 4th, Leary E, Lee SY, Carrillo O, Stubbs R, Peppard P, et al. Design and validation of a periodic leg movement detector. PLoS One. 2014;9(12):e114565. DOI: 10.1371/journal.pone.0114565

6. Montplaisir J, Boucher S, Poirier G, Lavigne G, Lapierre O, Lespérance P. Clinical, polysomnographic, and genetic characteristics of restless legs syndrome: a study of 133 patients diagnosed with new standard criteria. Mov Disord. 1997;12(1):61-5. DOI: 10.1002/mds.870120111

7. Kuchukhidze G, Toidze I, Khatiashvili I, Maisuradze L, Frauscher B, Kasradze $\mathrm{S}$, et al. Prevalence of restless legs syndrome in a Georgian primary healthcare setting: a pilot study. Eur Neurol. 2012;68(3):177-80. DOI 10.1159/000337938

8. Shin J, Koo YS, Lee BU, Shin WC, Lee SK, Cho YW, et al. Prevalence and Characteristics of Periodic Limb Movements during Sleep in Korean Adult Patients with Restless Legs Syndrome. J Clin Sleep Med. 2016;12(8):1089-97. DOI: 10.5664/jcsm.6042

9. Phillips B, Young T, Finn L, Asher K, Hening WA, Purvis C. Epidemiology of Restless Legs Symptoms in Adults. Arch Intern Med. 2000;160(14):2137-41. DOI: 10.1001/archinte.160.14.2137

10. Stefansson H, Rye DB, Hicks A, Petursson H, Ingason A, Thorgeirsson TE, et al. A genetic risk factor for periodic limb movements in sleep. New Eng J Med. 2007;357(7):639-47.

11. Allen RP, Connor JR, Hyland K, Earley CJ. Abnormally increased CSF 3-Ortho-methyldopa (3-OMD) in untreated restless legs syndrome (RLS) patients indicates more severe disease and possibly abnormally increased dopamine synthesis. Sleep Med. 2009;10(1):123-8. DOI: 10.1016/j. sleep.2007.11.012

12. Connor JR, Wang XS, Allen RP, Beard JL, Wiesinger JA, Felt BT, et al. Altered dopaminergic profile in the putamen and substantia nigra in restless leg syndrome. Brain. 2009;132(Pt 9):2403-12.

13. Earley CJ, Connor J, Garcia-Borreguero D, Jenner P, Winkelman J, Zee PC, et al. Altered brain iron homeostasis and dopaminergic function in Restless Legs Syndrome (Willis-Ekbom Disease). Sleep Med. 2014;15(11):1288-301.

14. Ferré S, Quiroz C, Guitart X, Rea W, Seyedian A, Moreno E, et al. Pivotal Role of Adenosine Neurotransmission in Restless Legs Syndrome. Front Neurosci. 2017;11:722.

15. Yepes G, Guitart X, Rea W, Newman AH, Allen RP, Earley CJ, et al. Targeting hypersensitive corticostriatal terminals in restless legs syndrome. Ann Neurol. 2017;82(6):951-60.

16. Winkelman JW, Armstrong MJ, Allen RP, Chaudhuri KR, Ondo W, Trenkwalder C, et al. Practice guideline summary: Treatment of restless legs syndrome in adults: Report of the Guideline Development, Dissemination, and Implementation Subcommittee of the American Academy of Neurology. Neurology. 2016;87(24):2585-93. DOI: 10.1212/ WNL.0000000000003388

17. Bega D, Malkani R. Alternative treatment of restless legs syndrome: an overview of the evidence for mind-body interventions, lifestyle interventions, and neutraceuticals. Sleep Med. 2016;17:99-105. DOI: 10.1016/j. sleep.2015.09.009

18. De Mello MT, Silva AC, Esteves AM, Tufik S. Reduction of periodic leg movement in individuals with paraplegia following aerobic physical exercise. Spinal Cord. 2002;40(12):646-9. DOI: 10.1038/sj.sc.3101381

19. De Mello MT, Esteves AM, Tufik S. Comparison between dopaminergic agents and physical exercise as treatment for periodic limb movements in patients with spinal cord injury. Spinal Cord. 2004;42(4):218-21. DOI: 10.1038/sj.sc.3101575

20. Pigeon WR, Yurcheshen M. Behavioral Sleep Medicine Interventions for Restless Legs Syndrome and Periodic Limb Movement Disorder. Sleep Med Clin. 2009;4(4):487-94. DOI: 10.1016/j.jsmc.2009.07.008

21. Esteves AM, de Mello MT, Pradella-Hallinan M, Tufik S. Effect of acute and chronic physical exercise on patients with periodic leg movements. Med Sci Sports Exerc. 2009;41(1):237-42. DOI: 10.1249/ MSS.0b013e318183bb22

22. Cavagnolli DA, Esteves AM, Castiglione ML, Batista IR, Bressan RA, Tufik S, et al. Dopamine transporter shown by SPECT in patients with periodic leg movement after acute physical exercise. Med Sci Sports Exerc. 2013;45(2):224-9. DOI: 10.1249/MSS.0b013e318270306c
23. Giannaki CD, Sakkas GK, Hadjigeorgiou GM, Karatzaferi C, Patramani G, Lavdas E, et al. Non-pharmacological management of periodic limb movements during hemodialysis session in patients with uremic restless legs syndrome. ASAIO J. 2010;56(6):538-42. DOI: 10.1097/ MAT.0b013e3181f1cc04

24. Maculano Esteves A, Ackel-D’Elia C, Tufik S, De Mello MT. Sleep patterns and acute physical exercise: the effects of gender, sleep disturbances, type and time of physical exercise. J Sports Med Phys Fitness. 2014;54(6):809-15.

25. de Mello MT, Lauro FA, Silva AC, Tufik S. Incidence of periodic leg movements and of the restless legs syndrome during sleep following acute physical activity in spinal cord injury subjects. Spinal Cord. 1996;34(5):294-6. DOI: 10.1038/sc.1996.53

26. Esteves AM, Lopes C, Frussa-Filho R, Frank MK, Cavagnolli D, Arida RM, et al. Spontaneously hypertensive rats: possible animal model of sleep-related movement disorders. J Mot Behav. 2013;45(6):487-93. DOI: 10.1080/00222895.2013.833079

27. Frank MK, de Mello MT, Lee KS, Daubian-Nosé P, Tufik S, Esteves AM. Sleep-related movement disorder symptoms in SHR are attenuated by physical exercise and an angiotensin-converting enzyme inhibitor. Physiol Behav. 2016;154:161-8. DOI: 10.1016/j.physbeh.2015.11.026

28. Esteves AM, Lopes C, Frank MK, Arida RM, Frussa-Filho R, Tufik S, et al. Can physical exercise have a protective effect in an animal model of sleep-related movement disorder? Brain Res. 2016;1639:47-57. DOI: 10.1016/j.brainres.2016.02.036

29. Rabelo PC, Almeida TF, Guimarães JB, Barcellos LA, Cordeiro LM, Moraes $\mathrm{MM}$, et al. Intrinsic exercise capacity is related to differential monoaminergic activity in the rat forebrain. Brain Res Bull. 2015;112:7-13. DOI: $10.1016 /$ j.brainresbull.2015.01.006

30. Rabelo PCR, Horta NAC, Cordeiro LMS, Poletini MO, Coimbra CC, Szawka RE, et al. Intrinsic exercise capacity in rats influences dopamine neuroplasticity induced by physical training. J Appl Physiol (1985). 2017;123(6):1721-9. DOI: 10.1152/japplphysiol.00506.2017

31. Aukerman MM, Aukerman D, Bayard M, Tudiver F, Thorp L, Bailey B. Exercise and restless legs syndrome: a randomized controlled trial. J Am Board Fam Med. 2006;19(5):487-93. DOI: 10.3122/jabfm.19.5.487

32. Esteves AM, De Mello MT, Benedito-Silva AA, Tufik S. Impact of aerobic physical exercise on Restless Legs Syndrome. Sleep Sci. 2011;4(2):45-8.

33. Mortazavi M, Vahdatpour B, Ghasempour A, Taheri D, Shahidi S, Moeinzadeh F, et al. Aerobic exercise improves signs of restless leg syndrome in end stage renal disease patients suffering chronic hemodialysis. Scientific WorldJournal. 2013;2013:628142. DOI: 10.1155/2013/628142

34. Giannaki CD, Hadjigeorgiou GM, Karatzaferi C, Maridaki MD, Koutedakis Y, Founta P, et al. A single-blind randomized controlled trial to evaluate the effect of 6 months of progressive aerobic exercise training in patients with uraemic restless legs syndrome. Nephrol Dial Transplant. 2013;28(11):2834-40. DOI: $10.1093 / \mathrm{ndt} / \mathrm{gft} 288$

35. Giannaki CD, Sakkas GK, Karatzaferi C, Hadjigeorgiou GM, Lavdas E, Kyriakides T, et al. Effect of exercise training and dopamine agonists in patients with uremic restless legs syndrome: a six-month randomized, partially double-blind, placebo-controlled comparative study. BMC Nephrol. 2013;14:194. DOI: 10.1186/1471-2369-14-194

36. Aliasgharpour M, Abbasi Z, Pedram Razi S, Kazemnezhad A. The Effect of Stretching Exercises on Severity of Restless Legs Syndrome in Patients on Hemodialysis. Asian J Sports Med. 2016;7(2):e31001. DOI 10.5812/asjsm.31001

37. Giannaki C, Sakkas G, Karatzaferi C, Maridaki M, Koutedakis Y, Hadjigeorgiou GM, et al. Combination of Exercise Training and Dopamine Agonists in Patients with RLS on Dialysis: A Randomized, Double-Blind Placebo-Controlled Study. ASAIO J. 2015;61(6):738-41. DOI: 10.1097/ MAT.0000000000000271

38. Ondo WG. Restless legs syndrome: pathophysiology and treatment. Curr Treat Options Neurol. 2014,16(11):317. DOI: 10.1007/s11940-014-0317-2

39. Lopes C, Esteves AM, Frussa-Filho R, Tufik S, de Mello MT. Evaluation of periodic limb movements in a putative animal model of restless leg syndrome. Mov Disord. 2012;27(3):413-20. DOI: 10.1002/mds.24058

40. Hening WA. Current guidelines and standards of practice for restless legs syndrome. Am J Med. 2007;120(1 Suppl 1):S22-7. DOI: 10.1016/j. amjmed.2006.11.004 